\title{
ANALYSIS OF ENTROPY GENERATION FOR MIXED CONVECTION FLUID FLOW IN A TRAPEZOIDAL ENCLOSURE USING THE MODIFIED BLOCKED REGION METHOD
}

\author{
Meysam Atashafrooz ${ }^{1, *}$, Mohsen Shafie ${ }^{2}$ \\ ${ }^{1}$ Department of Mechanical Engineering, Sirjan University of Technology, Sirjan, Iran \\ E-mail:m.atashafrooz@sirjantech.ac.ir, Meysam.atashafrooz@yahoo.com \\ ${ }^{2}$ Department of Mechanical Engineering, Sirjan Branch, Islamic Azad University, Sirjan, Iran \\ E-mail: m.shafie845@yahoo.com \\ *corresponding author
}

\begin{abstract}
In this research, analysis of entropy generation for mixed convection fluid flow in a trapezoidal enclosure is numerically investigated. To achieve this goal, the influences of Grashof number, Reynolds number and inclination angle of enclosure side walls on the distributions of the velocity and temperature fields and the values of entropy generation and Bejan numbers are examined with full details. The Boussinesq approximation is used to calculate the buoyancy force. Also, the entropy generation numbers are calculated according to the second law of thermodynamics. In addition, the modified blocked region method is applied to accurately simulate the diagonal walls of the trapezoidal enclosure. The results of numerical solution show that the maximum values of the flow irreversibility in the whole computational domain of the enclosure are related to the case with the highest values of Grashof number, Reynolds number and inclination angle of side walls.
\end{abstract}

Keywords: Entropy generation, irreversibility, mixed convection, trapezoidal enclosure, modified blocked region method.

\section{Introduction}

Analysis of mixed convection fluid flow in different enclosures is one of the important issues in the design of thermal engineering systems (Wu et al. 2011, Kefayati et al. 2012, Atashafrooz and Nassab 2013, Nithyadevi and Begum 2017, Yu et al. 2018). These types of fluid flows are found in many industrial and engineering applications, such as the electronics cooling systems, heat exchangers and solar pools. So far, several researchers studied the mixed convection flow in different enclosures (Stiebler et al. 2011, Bhattacharya et al. 2013, Ismael et al. 2014, Ali et al. 2017, Sajjadi et al. 2018, Sheikholeslami et al. 2019). Among these researches, Revnic et al. (2011) studied the unsteady free convection flow in a square enclosure filled with a porous medium in the presence of a magnetic field. In another research, Mohammadi and Nassab (2015) analyzed the interaction influences of thermal radiation and mixed convection flow in a trapezoidal enclosure. They reported that the optical thickness and radiation-conduction parameter have the considerable effects on the heat transfer rates. Mahmoodabadi et al. 
(2018) developed and applied the meshless local Petrov-Galerkin algorithm to simulate the threedimensional incompressible flow in a cubic enclosure. Sajjadi et al. (2019) investigated the role of buoyancy and magnetic forces on the hydrothermal behaviors of fluid flow in a cubic enclosure. In that study, researchers applied the double MRT Lattice Boltzmann method to solve the governing equations. In a recent study, Chamkha et al. (2020) used the finite volume method to study the influences of Hartmann and Richardson numbers on the magneto-ferrofluid mixed convection flow inside a square enclosure with partial slip.

In the above studies, various methods have been proposed to control (increase or decrease) the heat transfer rate in different systems. However, it should be noted that most of the mentioned methods significantly affect the efficiency of these systems. Therefore, in addition to controlling the heat transfer rate, the energy optimization of thermal systems is very important and should also be studied (Bejan 1994, Bejan 1996, Aghaei et al. 2016, Atashafrooz et al. 2019). Theoretical and experimental studies show that the reducing the rate of flow irreversibility is the most important way to reduce the energy consumption in engineering and thermal systems (Bejan 1994, Bejan 1996, Aghaei et al. 2016, Atashafrooz et al. 2019).

So far, many different techniques have been presented by researchers to determine the rate of flow irreversibility. Among these techniques, analysis of the thermodynamics second law (entropy generation analysis) is a useful method and plays an important role in determining the optimal conditions for engineering systems (Erbay et al. 2004, Atashafrooz and Asadi 2019). This analysis has been applied by many researchers to investigate the flow irreversibility in various geometries (Kooshki et al. 2012, Bahaidarah and Sahin 2013, Mohaghegh and Esfahani 2016). Some of these researches are related to calculating the amount of entropy generation in open and closed enclosures (Atashafrooz et al. 2014, Malik and Nayak 2017, Dutta et al. 2018, Atashafrooz et al. 2020). Among these studies, Dagtekin et al. (2007) analyzed the entropy generation for the free convection flow in a $\Gamma$-shaped enclosure. Mamourian et al. (2016) applied the Taguchi approach to optimize the entropy generation for mixed convection flow in a square enclosure with wavy surfaces. Oztop et al. (2017) studied the entropy generation for the free convection flow in a three-dimensional partially open enclosure. They found that the geometrical characteristics of enclosure and the Rayleigh number have the significant impacts on the values of entropy generation number. In another research, Seyyedi et al. (2020) analyzed the entropy generation for nanofluid flow in a L-shaped enclosure in the existence of an inclined magnetic field.

As it is mentioned above, the analysis of flow irreversibility is of great importance in the design of engineering systems. Although, several researches have been so far performed to study this issue in different geometries; but to the best of author's knowledge, analysis of entropy generation for mixed convection fluid flow in a complex trapezoidal enclosure have not been done enough by previous researchers. Therefore, an attempt is made in the present research to study this important and industrial issue. In fact, the main purpose of this study is to obtain the optimal conditions to reduce the irreversibility rate of mixed convection flow in the mentioned enclosure. To achieve this goal, the effects of Grashof number, Reynolds number and inclination angle of side walls on the amount of entropy generation are discussed in detail and thoroughly. In addition, it is important to note that in order to accurately simulate the diagonal walls of the trapezoidal enclosure, the modified blocked region method is applied.

\section{Problem Description}

The problem geometry of the present study is a trapezoidal enclosure. This enclosure has two independent inlet and outlet ducts. The schematic of this enclosure along with its related geometric dimensions are presented in Figure 1 and Table 1. 


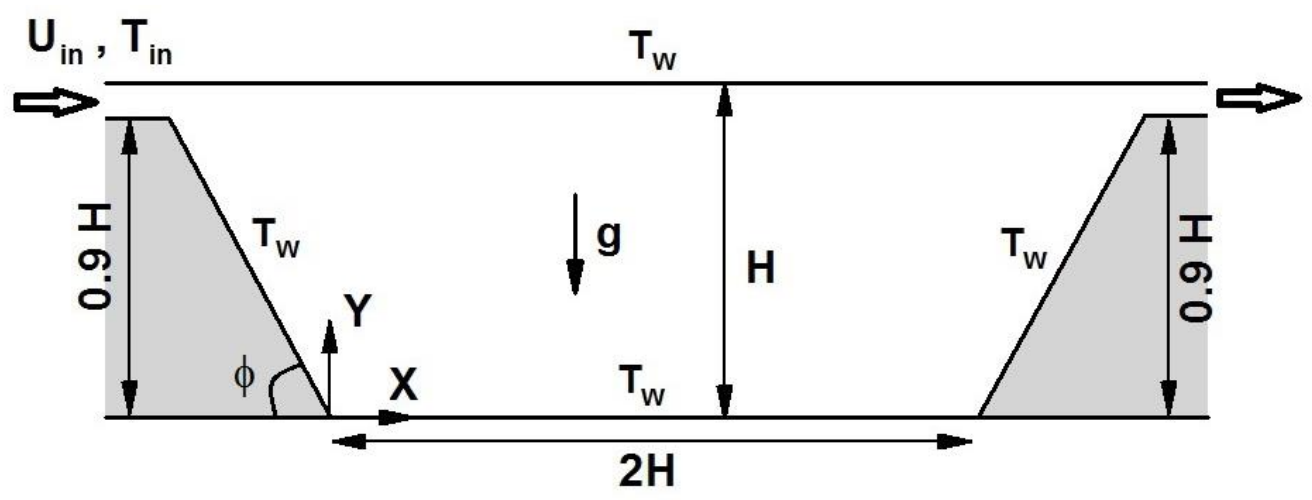

Fig. 1. Geometry and physical configuration of the enclosure under study

\begin{tabular}{|c|c|}
\hline Length of the enclosure bottom wall & $2 H$ \\
\hline Enclosure height & $H$ \\
\hline Height of the enclosure side walls & $0.9 H$ \\
\hline Height of the flow inlet section & $0.1 \mathrm{H}$ \\
\hline Height of the flow outlet section & $0.1 \mathrm{H}$ \\
\hline Inclination angle of the enclosure side walls & $\Phi=50^{\circ}-70^{\circ}$ \\
\hline
\end{tabular}

Table 1. Geometric dimensions of the enclosure under study

Also, the hydrodynamic (flow) and thermal boundary conditions of this enclosure are presented in Table 2 .

\begin{tabular}{|c|c|c|}
\hline & $\begin{array}{c}\text { Flow boundary } \\
\text { conditions }\end{array}$ & $\begin{array}{c}\text { Thermal boundary } \\
\text { conditions }\end{array}$ \\
\hline $\begin{array}{c}\text { The enclosure walls (include } \\
\text { the bottom, top and side } \\
\text { walls) }\end{array}$ & $u=0, v=0$ & $T=T_{W}$ \\
\hline The flow inlet section & $u=U_{i n}, v=0$ & $T=T_{i n}$ \\
\hline
\end{tabular}

Table 2. Flow and thermal boundary conditions

\section{Governing Equations}

To calculate the amount of the flow irreversibility in the enclosure under study, the velocity and temperature fields are first needed. To determine the velocity and temperature fields, the governing equations should be solved. Theses governing equations for mixed convection fluid flow include the conservation of mass, momentum, and energy equations. For two-dimensional, incompressible, steady and laminar flow, these equations can be presented as follows:

$$
\frac{\partial u}{\partial x}+\frac{\partial v}{\partial y}=0
$$




$$
\begin{gathered}
\mathrm{u} \frac{\partial \mathrm{u}}{\partial \mathrm{x}}+\mathrm{v} \frac{\partial \mathrm{u}}{\partial \mathrm{y}}=-\frac{1}{\rho} \frac{\partial \mathrm{p}}{\partial \mathrm{x}}+\frac{\mu}{\rho}\left(\frac{\partial^{2} \mathrm{u}}{\partial \mathrm{x}^{2}}+\frac{\partial^{2} \mathrm{u}}{\partial \mathrm{y}^{2}}\right) \\
\mathrm{u} \frac{\partial \mathrm{v}}{\partial \mathrm{x}}+\mathrm{v} \frac{\partial \mathrm{v}}{\partial \mathrm{y}}=-\frac{1}{\rho} \frac{\partial \mathrm{p}}{\partial \mathrm{y}}+\frac{\mu}{\rho}\left(\frac{\partial^{2} \mathrm{v}}{\partial \mathrm{x}^{2}}+\frac{\partial^{2} \mathrm{v}}{\partial \mathrm{y}^{2}}\right)+\beta g\left(T-T_{i n}\right) \\
\mathrm{u} \frac{\partial \mathrm{T}}{\partial \mathrm{x}}+\mathrm{v} \frac{\partial \mathrm{T}}{\partial \mathrm{y}}=\alpha\left(\frac{\partial^{2} \mathrm{~T}}{\partial \mathrm{x}^{2}}+\frac{\partial^{2} \mathrm{~T}}{\partial \mathrm{y}^{2}}\right)
\end{gathered}
$$

It should be mentioned that the last term on the right-hand side of equation (3) is related to the contribution of buoyancy force, which is calculated by the Boussinesq approximation.

Also, the dimensionless forms of these governing equations (continuity, momentum and energy) are expressed as follows:

$$
\begin{gathered}
\frac{\partial \mathrm{U}}{\partial \mathrm{X}}+\frac{\partial \mathrm{V}}{\partial \mathrm{Y}}=0 \\
\frac{\partial}{\partial \mathrm{X}}\left(\mathrm{U}^{2}-\frac{1}{\operatorname{Re}} \frac{\partial \mathrm{U}}{\partial \mathrm{X}}\right)+\frac{\partial}{\partial \mathrm{Y}}\left(\mathrm{UV}-\frac{1}{\operatorname{Re}} \frac{\partial \mathrm{U}}{\partial \mathrm{Y}}\right)=-\frac{\partial \mathrm{P}}{\partial \mathrm{X}} \\
\frac{\partial}{\partial \mathrm{X}}\left(\mathrm{UV}-\frac{1}{\operatorname{Re}} \frac{\partial \mathrm{V}}{\partial \mathrm{X}}\right)+\frac{\partial}{\partial \mathrm{Y}}\left(\mathrm{V}^{2}-\frac{1}{\operatorname{Re}} \frac{\partial \mathrm{V}}{\partial \mathrm{Y}}\right)=-\frac{\partial \mathrm{P}}{\partial \mathrm{Y}}+\frac{G r}{\mathrm{Re}^{2}} \Theta \\
\frac{\partial}{\partial \mathrm{X}}\left(\mathrm{U} \Theta-\frac{1}{\mathrm{Pe}} \frac{\partial \Theta}{\partial \mathrm{X}}\right)+\frac{\partial}{\partial \mathrm{Y}}\left(\mathrm{V} \Theta-\frac{1}{\mathrm{Pe}} \frac{\partial \Theta}{\partial \mathrm{Y}}\right)=0
\end{gathered}
$$

It should be noted that in presenting the above equations, the following dimensionless parameters have been used:

$$
\begin{aligned}
& (\mathrm{X}, \mathrm{Y})=\left(\frac{\mathrm{x}}{H}, \frac{\mathrm{y}}{H}\right),(U, V)=\left(\frac{u}{U_{\text {in }}}, \frac{v}{U_{\text {in }}}\right), P=\frac{p}{\rho U_{i n}^{2}}, \Theta=\frac{\mathrm{T}-\mathrm{T}_{\text {in }}}{\mathrm{T}_{\mathrm{w}}-\mathrm{T}_{\mathrm{in}}} \\
& \operatorname{Pr}=\frac{v}{\alpha}, \operatorname{Re}=\frac{\rho U_{i n} H}{\mu}, \operatorname{Pe}=\operatorname{Re} \operatorname{Pr}, G r=\frac{\beta g\left(T_{W}-T_{\text {in }}\right) H^{3}}{v^{2}}
\end{aligned}
$$

\subsection{Entropy Generation Analysis}

As it is mentioned before, the main purpose of this study is to obtain the entropy generation rate as a criterion for determining the rate of flow irreversibility in the enclosure under study. According to the second law of thermodynamics, for mixed convection fluid flow, the entropy generation rate $\left(S_{g}\right)$ is the sum of the entropy generation rates due to conductive heat transfer $\left(\left(S_{g}\right)_{c}\right)$ and the viscous fluid flow $\left(\left(S_{g}\right)_{v}\right)$ (Mohaghegh and Esfahani 2016, Atashafrooz and Asadi 2019):

$$
S_{g}=\left(S_{g}\right)_{c}+\left(S_{g}\right)_{v}
$$




$$
\begin{gathered}
\left(S_{g}\right)_{c}=\frac{k}{T_{i n}{ }^{2}}\left[\left(\frac{\partial T}{\partial \mathrm{x}}\right)^{2}+\left(\frac{\partial T}{\partial \mathrm{y}}\right)^{2}\right] \\
\left(S_{g}\right)_{v}=\frac{k}{T_{i n}^{2}}\left\{2 \times\left[\left(\frac{\partial \mathrm{u}}{\partial \mathrm{x}}\right)^{2}+\left(\frac{\partial \mathrm{v}}{\partial \mathrm{y}}\right)^{2}\right]+\left[\left(\frac{\partial \mathrm{u}}{\partial \mathrm{y}}\right)+\left(\frac{\partial \mathrm{v}}{\partial \mathrm{x}}\right)\right]^{2}\right\}
\end{gathered}
$$

Also, the dimensionless form of Equations (10) to (13) can be formulated as follows (Kooshki et al. 2012, Atashafrooz and Asadi 2019):

$$
\begin{gathered}
N s=N s_{c}+N s_{v} \\
N s_{c}=\left[\left(\frac{\partial \Theta}{\partial \mathrm{X}}\right)^{2}+\left(\frac{\partial \Theta}{\partial \mathrm{Y}}\right)^{2}\right] \\
N s_{v}=\Psi\left\{2 \times\left[\left(\frac{\partial \mathrm{U}}{\partial \mathrm{X}}\right)^{2}+\left(\frac{\partial \mathrm{V}}{\partial \mathrm{Y}}\right)^{2}\right]+\left[\left(\frac{\partial \mathrm{U}}{\partial \mathrm{Y}}\right)+\left(\frac{\partial \mathrm{V}}{\partial \mathrm{X}}\right)\right]^{2}\right\}
\end{gathered}
$$

In the above equations, the following dimensionless relations are used:

$$
\mathrm{Ns}=\frac{S_{g} T_{i n}{ }^{2} H^{2}}{k\left(T_{W}-T_{i n}\right)^{2}}, \Psi=\frac{\mu T_{i n} U_{i n}{ }^{2}}{k\left(T_{W}-T_{i n}\right)^{2}}
$$

Besides, the total entropy generation numbers can be calculated as (Kooshki et al. 2012, Atashafrooz and Asadi 2019):

$$
\left.\left.\left.\left.\mathrm{Ns})_{\mathrm{t}}=\mathrm{Ns}_{\mathrm{c}}\right)_{\mathrm{t}}+\mathrm{Ns}_{\mathrm{v}}\right)_{t}=\iint_{\forall}\left[\mathrm{Ns}_{\mathrm{c}}\right)_{\mathrm{t}}+\mathrm{Ns}_{\mathrm{v}}\right)_{t}\right] \mathrm{d} X d Y
$$

Another important parameter in studying the flow irreversibility is the Bejan number $(\mathrm{Be})$. This number represents the ratio of entropy generation due to conductive heat transfer to total entropy generation and is calculated as follow (Kooshki et al. 2012, Atashafrooz and Asadi 2019):

$$
\mathrm{Be}=\frac{\mathrm{Ns}_{\mathrm{c}}}{\mathrm{Ns}_{\mathrm{c}}+N s_{v}}
$$

\section{Numerical Solution and Code Validation}

\subsection{Numerical Solution}

To obtain the velocity and temperature fields in the studied enclosure, the governing equations (continuity, momentum and energy) are first discretized using the finite volume method and by integration on the volume of each element. Then, these discrete equations are solved using the SIMPLE algorithm (Patankar and Spalding 1972) and line-by-line iterative method.

It should be noted that the flow velocity field are obtained using the staggered control volumes; whereas, the pressure and temperature fields are calculated on the main nodes. Also, the convergence criterions for the numerical solution of the governing equations are considered as follows: 


$$
\begin{gathered}
\operatorname{Error} \Phi=\operatorname{Max}\left|\frac{\Phi^{n}(i, j)-\Phi^{n-1}(i, j)}{\Phi^{n}(i, j)}\right| \leq 10^{-6} \\
\operatorname{Error} \Phi=\sum_{i=1}^{i=I N} \sum_{j=1}^{j=J N}\left|\Phi^{n}(i, j)-\Phi^{n-1}(i, j)\right| \leq 10^{-5}
\end{gathered}
$$

In the above equations, the $\Phi$ symbol represents the pressure, velocity and temperature fields. Also, the index $n$ denotes the iteration step.

In the present study, a grid size of $340 \times 200(X \times Y)$ has been obtained as the optimal mesh. It should be noted that for more accurate results, this mesh is denser and clustered near the enclosure walls.

\subsection{Modified Blocked Region Method}

In this research, the modified blocked region (embedded boundary) method is used to simulate the diagonal surfaces of the trapezoidal enclosure (Zabihi et al. 2017).

The modified blocked region method is almost similar to the blocked-off method (Atashafrooz et al. 2014). In fact, the difference between two these methods is related to simulate the inclined or curved walls. The modified blocked region method includes drawing a nominal domain around the main (physical or real) domain. Then, to make a distinction between the cells in the active and inactive regions a "domain file" is created for each geometry. A schematic of an irregular complex geometry and its nominal domain is shown in Figures 2. In this figure, cells A and $\mathrm{D}$ are respectively the active and inactive cells.

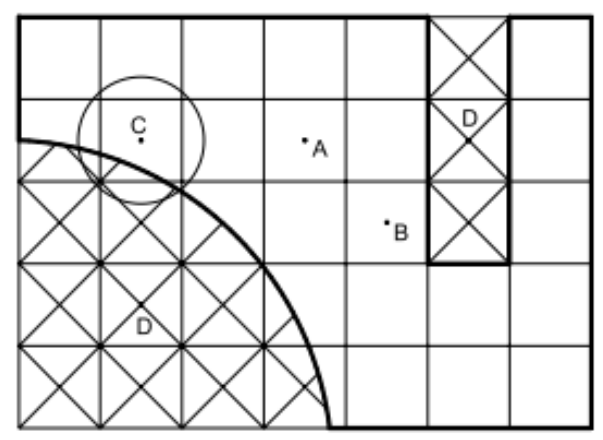

Fig. 2. Simulation of an irregular complex geometry using the modified blocked region method (Zabihi et al. 2017)

In addition, the location of the inner boundaries in the nominal domain is set and a "boundary condition file" is defined for these boundaries. For those inner boundaries that are parallel to the coordinates axis, the boundary condition file involves those control volumes (CV) in the physical domain that are near to the inner boundaries (Please see cell B in Figure 2).

But, for curved and inclined inner boundaries, the boundary condition file involves cells that have an intersection with the inner boundary (Please see cell $\mathrm{C}$ in Figure 2). It should be mentioned that using the modified blocked region method, the inclined or curved surfaces are modeled exactly the same as the real irregular surfaces. More details of this method were explained by Zabihi et al. (2017). 


\subsection{Code Validation}

To check the accuracy of the computer program in solving the governing equations, the values of average Nusselt number on the bottom wall of a square enclosure are compared with the numerical findings of Iwatsu et al. (1993) in Table 3.

\begin{tabular}{|c|c|c|c|}
\hline Grashof number & Reynolds number & Iwatsu et al. (1993) & Present study \\
\hline \multirow{2}{*}{$G r=100$} & $\mathrm{Re}=100$ & 1.85 & 1.89 \\
\cline { 2 - 4 } & $\mathrm{Re}=400$ & 3.76 & 3.81 \\
\hline \multirow{2}{*}{$G r=10000$} & $\mathrm{Re}=100$ & 1.30 & 1.32 \\
\cline { 2 - 4 } & $\mathrm{Re}=400$ & 3.57 & 3.60 \\
\hline
\end{tabular}

Table 3. Comparison of the average Nusselt number with the results of Iwatsu et al. (1993)

This comparison is done for different values of Grashof and Reynolds numbers. As it is clear from Table 3, there is a good consistency between the results of the present study and Iwatsu et al. (1993).

In order to further evaluate the validity of the numerical calculations performed in the present study, the variations of the entropy generation number on the bottom wall of a rectangular duct having step are compared with the results presented by Kooshki, et al. (2012) in Figure 3. As it is seen from this figure, the algorithm used in this research has an acceptable accuracy.

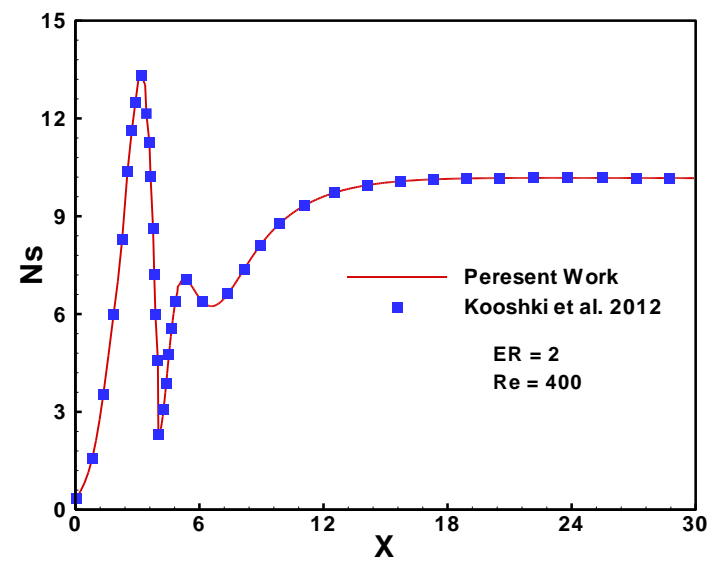

Fig. 3. Comparison of the entropy generation number on the bottom wall of a rectangular duct having step with the results of Kooshki, et al. (2012)

\section{Results and Discussions}

First, to obtain the buoyancy force influence on the hydrodynamic and thermal patterns of mixed convection fluid flow, distributions of the axial velocity and temperature fields in the enclosure under study are presented in Figures 4 and 5 at two different values of Grashof number $(\mathrm{Gr})$. A detailed analysis of the results presented in these figures shows that the Grashof number has a significant effect on both the trends and values of the velocity and temperature fields, especially 
near the enclosure walls. Therefore, it can be predicted that the amount of flow irreversibility is also significantly dependent on the values of the buoyancy force.

To analyze this issue, distributions of entropy generation numbers (Ns) on the bottom wall of enclosure are shown in Figure 6 at five different values of the Grashof number. Careful analysis of this figure reveals that the values of entropy generation number increase significantly by enhancing the magnitudes of Grashof number. To find out the reason for this increase, distributions of entropy generation numbers due to conductive heat transfer $\left(\mathrm{Ns}_{\mathrm{c}}\right)$ and viscous fluid flow $\left(\mathrm{Ns}_{\mathrm{v}}\right)$ are shown in Figures 7 and 8 at different values of Grashof number. A careful examination of these two figures shows that an enhancement in the magnitudes of Grashof number results in a significant increase in the amounts of the $\mathrm{Ns}_{\mathrm{c}}$ and $\mathrm{Ns}_{\mathrm{v}}$. Therefore, it can be said with certainty that the reason for the enhancement of the $\mathrm{Ns}$ values against the $\mathrm{Gr}$ is due to the increase of the magnitudes of the $\mathrm{Ns}_{\mathrm{c}}$ and $\mathrm{Ns}_{\mathrm{v}}$.

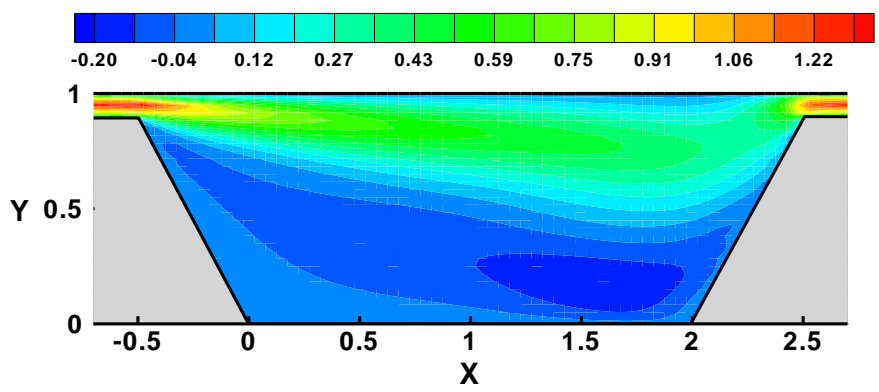

(a) $\mathrm{Gr}=0$

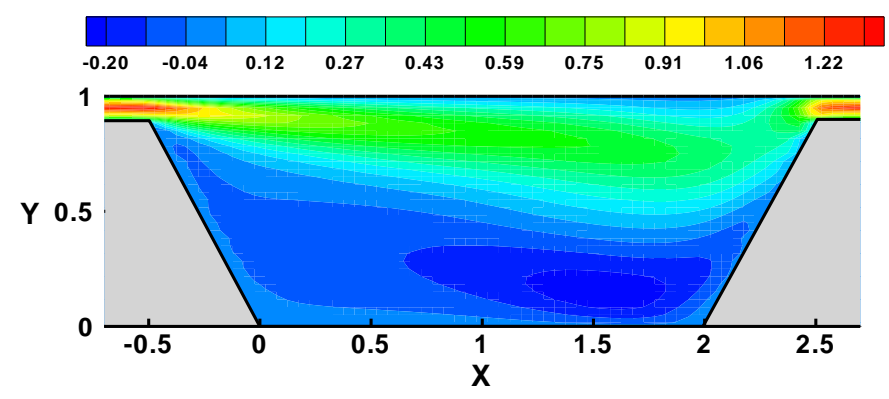

(b) $\mathrm{Gr}=200000$

Fig. 4. Influence of Grashof number on the axial velocity fields in the enclosure under study 


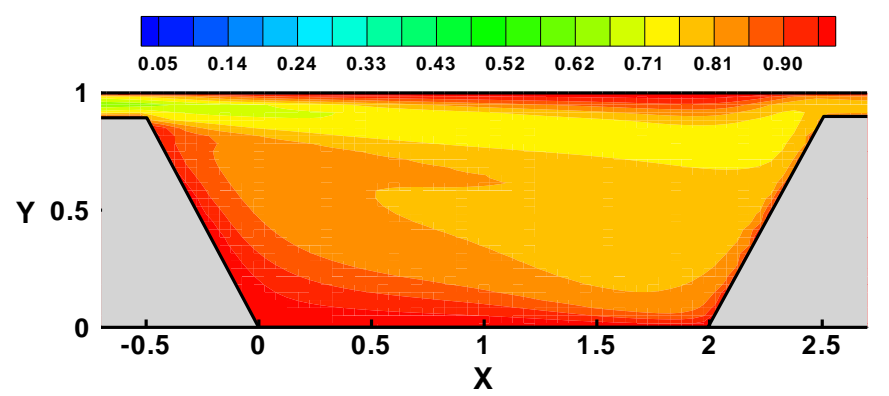

(a) $\mathrm{Gr}=0$

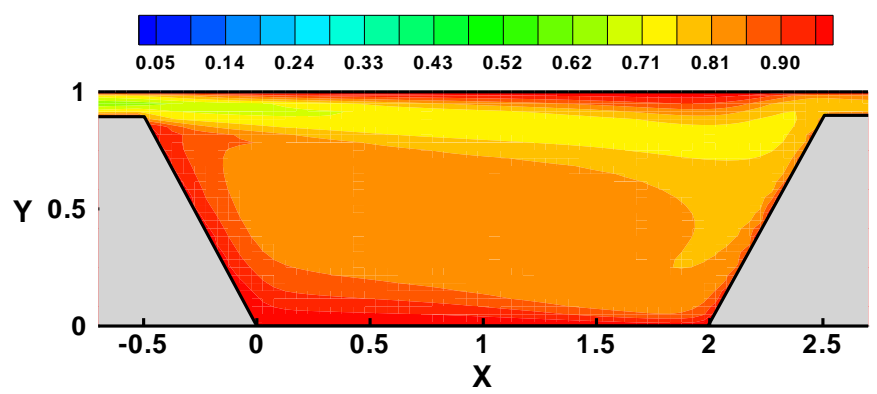

(b) $\mathrm{Gr}=200000$

Fig. 5. Influence of Grashof number on the temperature fields in the enclosure under study

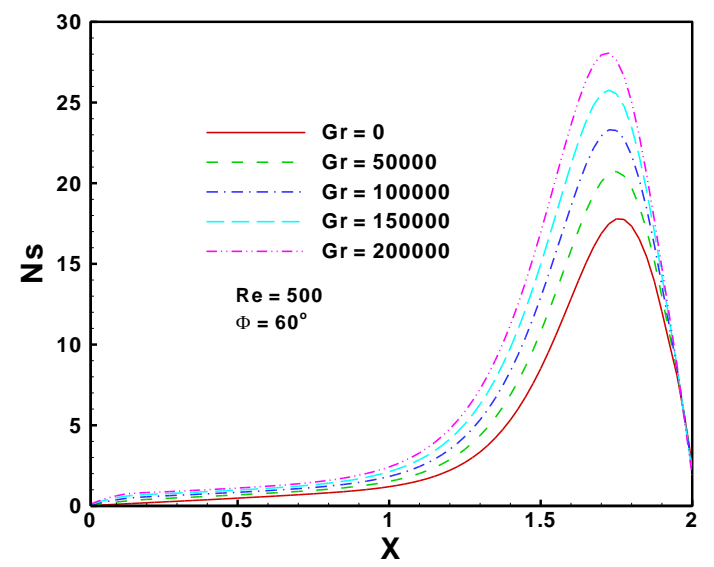

Fig. 6. Influence of Grashof number on the distributions of entropy generation numbers along the bottom wall of enclosure under study 


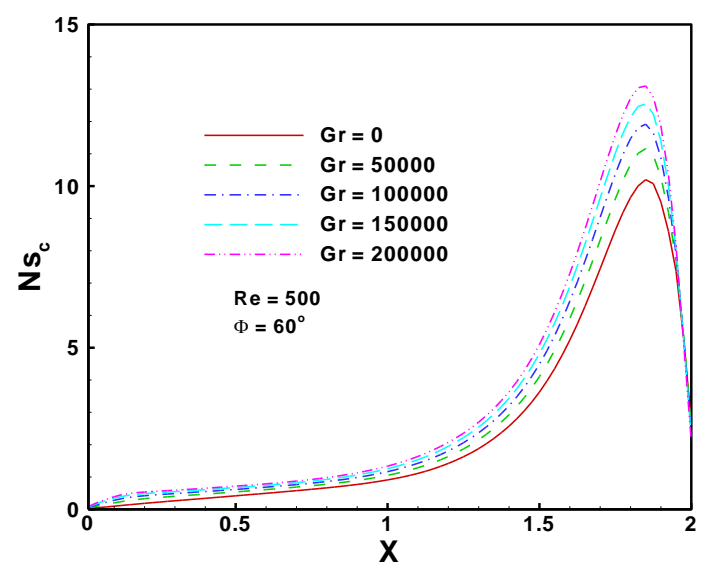

Fig. 7. Influence of Grashof number on the distributions of entropy generation numbers due to conductive heat transfer along the bottom wall of enclosure under study

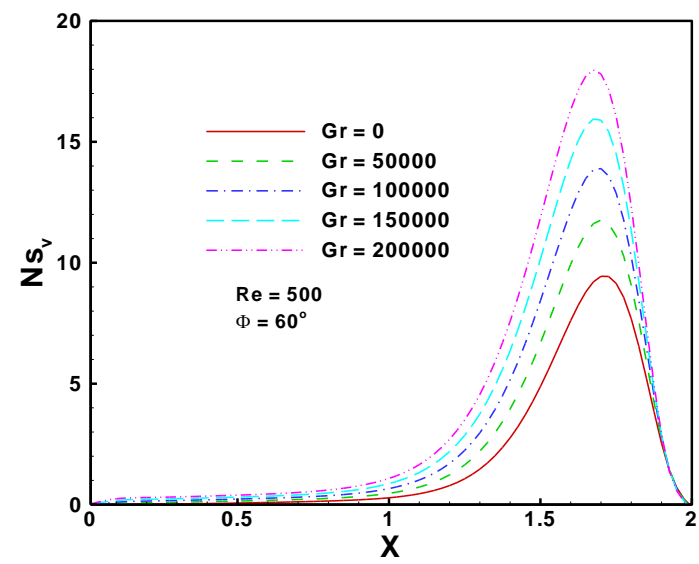

Fig. 8. Influence of Grashof number on the distributions of entropy generation numbers due to viscous fluid flow along the bottom wall of enclosure under study

To further study the impacts of the buoyancy force on the rates of flow irreversibility, the values of total entropy generation numbers $\left.(\mathrm{Ns})_{t}\right)$ in the whole computational domain of the enclosure under study are presented in Figure 9 for five different values of the Grashof number. As can be seen from this figure, the flow irreversibility rate (total entropy generation number) enhances significantly as the Grashof number increases. 


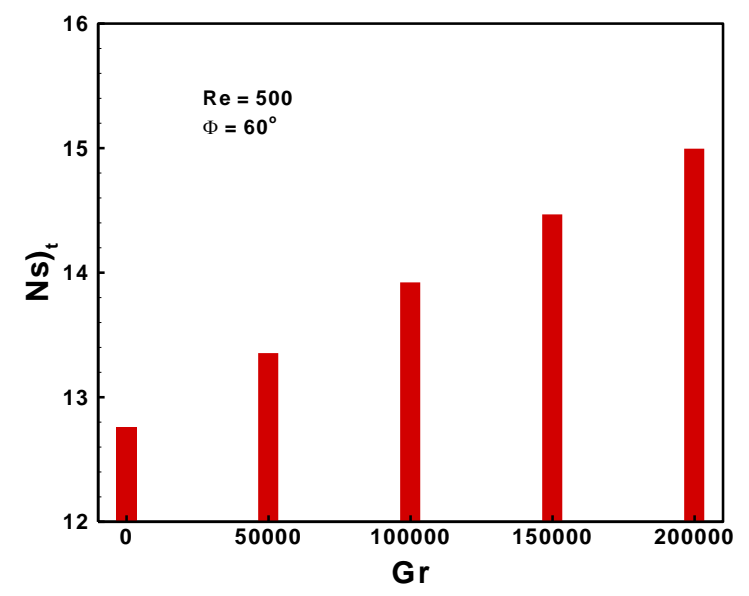

Fig. 9. Influence of Grashof number on the values of total entropy generation numbers along the bottom wall of enclosure under study

It can be said that this increase is due to the fact that two effective terms on Ns) including the total entropy generation numbers due to conductive heat transfer $\left.\left(\mathrm{Ns}_{\mathrm{c}}\right)_{\mathrm{t}}\right)$ and viscous fluid flow $\left.\left(\mathrm{Ns}_{\mathrm{v}}\right)_{t}\right)$ increase against the Grashof number (Please see Figures 10 and 11).



Fig. 10. Influence of Grashof number on the values of total entropy generation numbers due to conductive heat transfer along the bottom wall of enclosure under study 


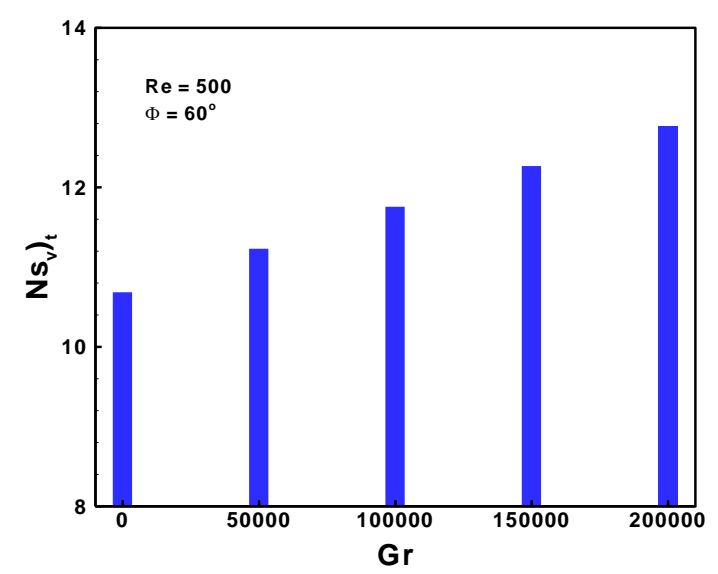

Fig. 11. Influence of Grashof number on the values of total entropy generation numbers due to viscous fluid flow along the bottom wall of enclosure under study

As it is mentioned before, one of the important parameters in the study of the flow irreversibility is the Bejan number (Be). Figures 12 (a) and (b) are presented to analyze the effects of the buoyancy force on the values of this parameter in the enclosure under study. In these figures, distributions of the Bejan number are shown at two different values of Grashof number. As can be seen from these figures, a decrease in the values of the Bejan number is registered by increasing the Grashof number. In other words, the highest values of Bejan number are related to the pure forced convection fluid flow. Based on the definition of Bejan number, it can be said that the contribution of total entropy number due to conductive heat transfer decreases significantly by increasing the Grashof number.

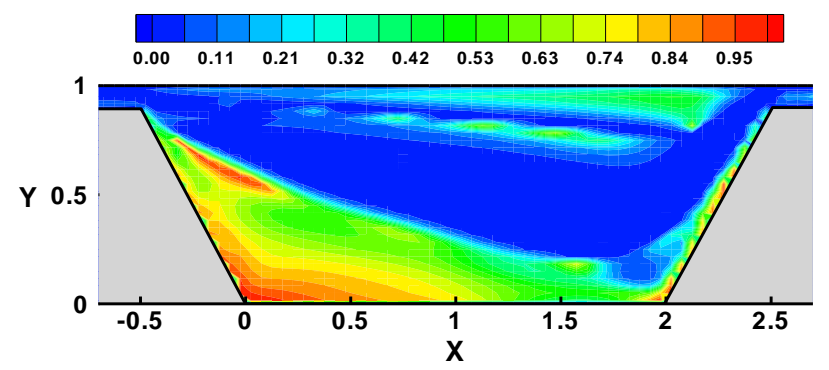

(a) $\mathrm{Gr}=0$

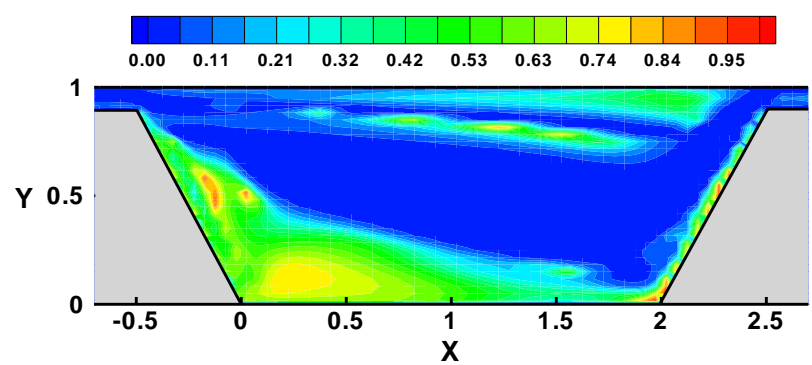

(b) $\mathrm{Gr}=200000$

Fig. 12. Influence of Grashof number on the Bejan number fields in the enclosure under study 


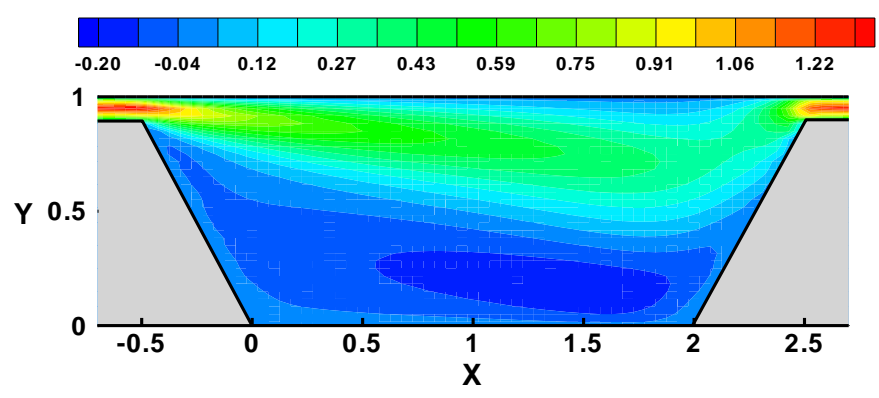

(a) $\mathrm{Re}=400$

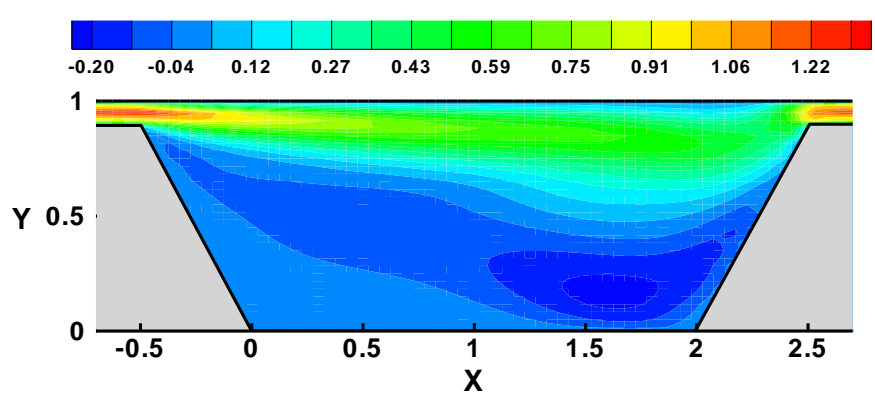

(b) $\mathrm{Re}=800$

Fig. 13. Influence of Reynolds number on the axial velocity fields in the enclosure under study

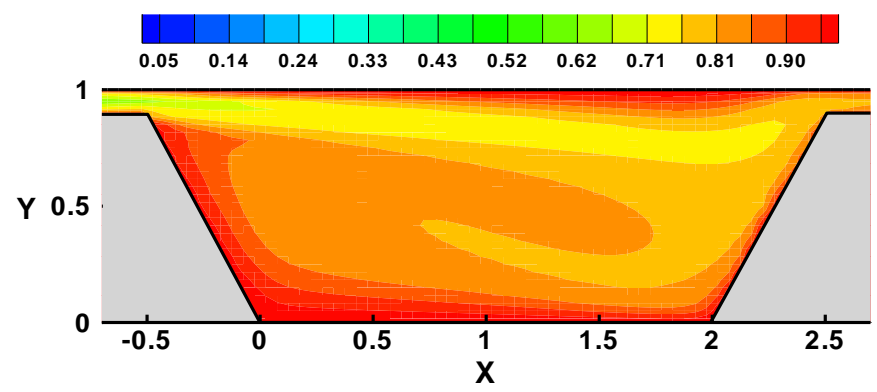

(a) $\mathrm{Re}=400$

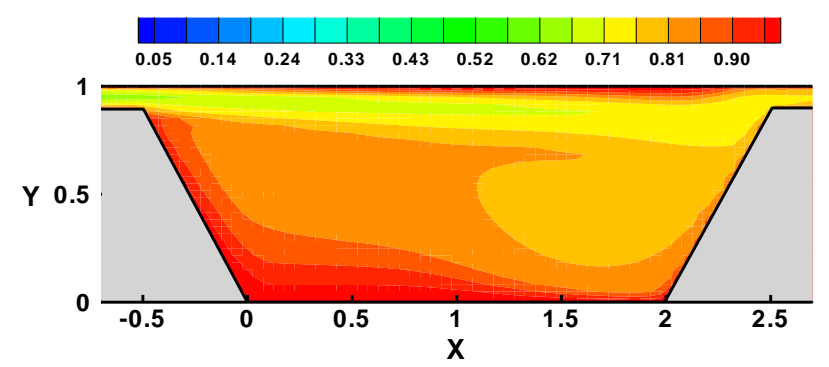

(b) $\mathrm{Re}=800$

Fig. 14. Influence of Reynolds number on the temperature fields in the enclosure under study 
To study the effects of Reynolds number $(\mathrm{Re})$ on the flow and thermal behaviors in the enclosure under study, distributions of dimensionless axial velocity and temperature fields are shown in Figures 13 and 14. As it is clear from these figures, the values and trends of velocity and temperature fields are dependent on the values of Reynolds number. Besides, a detailed analysis of the results shows that the Reynolds number has a significant effect on the gradients of velocity and temperature near the enclosure walls, especially near the bottom wall.

Therefore, it can be expected that the amount of the flow irreversibility are significantly dependent on the magnitudes of Reynolds number. To investigate this issue, distributions of entropy generation number on the bottom wall of enclosure are presented in Figure 15 for five different values of Reynolds number. As can be seen from this figure, there is a dual behavior for the variations of entropy generation number on the bottom wall of the enclosure in terms of Reynolds number. In fact, in the areas near the right wall of enclosure, the values of the entropy generation number enhance with increasing Reynolds number; whilst in other areas, this behavior is reversed.

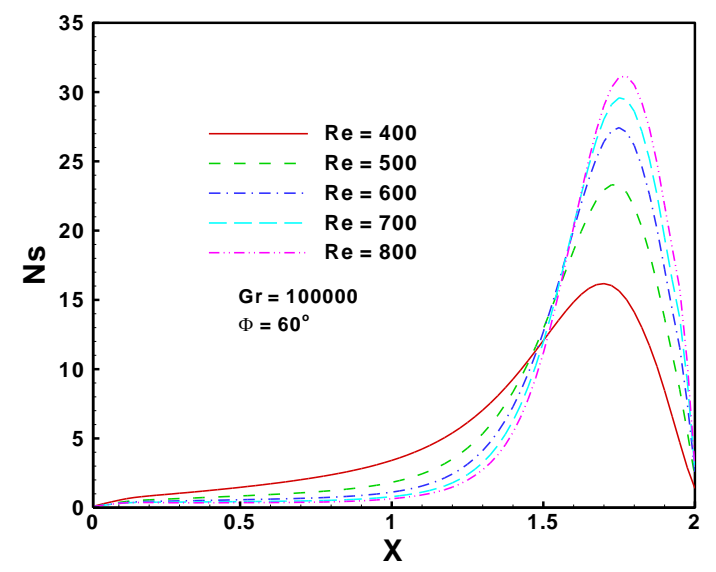

Fig. 15. Influence of Reynolds number on the distributions of entropy generation numbers along the bottom wall of enclosure under study

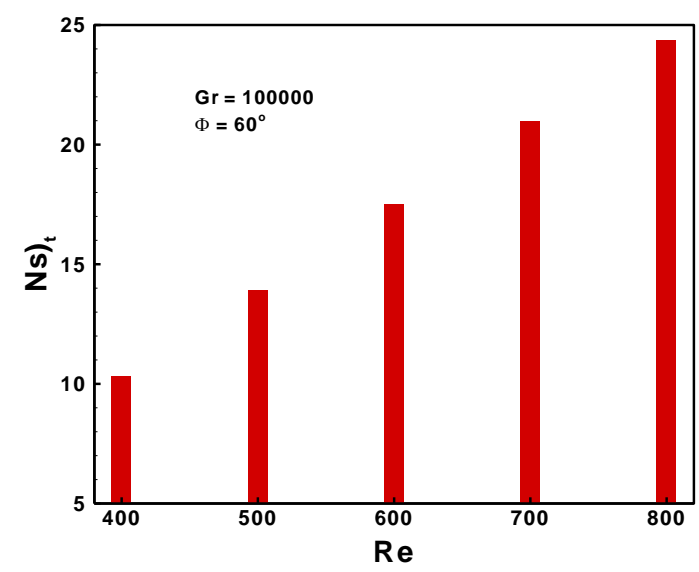

Fig. 16. Influence of Reynolds number on the values of total entropy generation numbers along the bottom wall of enclosure under study 
To better understand the effects of Reynolds number on the rates of flow irreversibility, the values of total entropy generation numbers in whole computational domain of enclosure under study are presented in Figure 16. It is clear from this figure that the rates of flow irreversibility increase significantly with raising the Reynolds number.

To determine the contribution of total entropy generation due to conductive heat transfer in the amounts of the flow irreversibility in the enclosure under study, distributions of Bejan number fields are presented in Figures 17 (a) and (b) for two values of Reynolds number. These figures clearly show that the values of the Bejan number increase as the Reynolds number increases. Therefore, it can be said that the contribution of conductive heat transfer in values of the total entropy generation number increases significantly with increasing the Reynolds number.

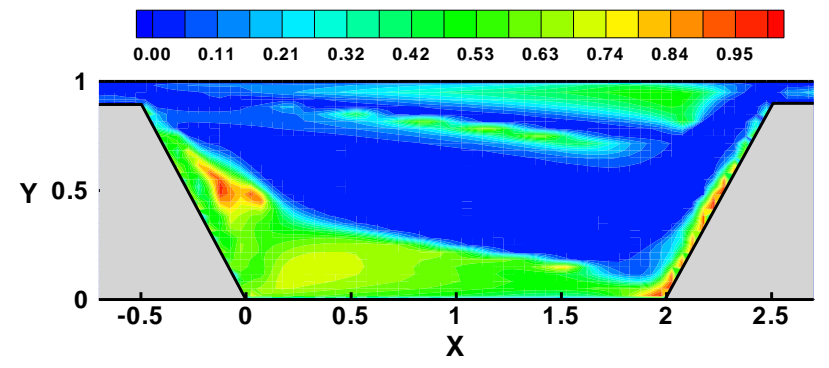

(a) $\operatorname{Re}=400$

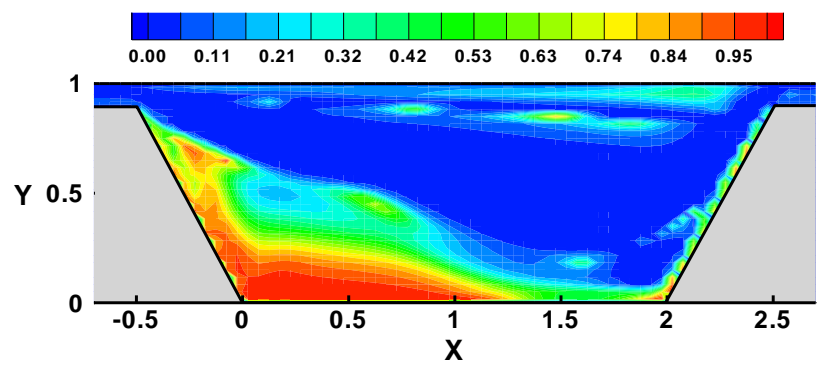

(b) $\mathrm{Re}=800$

Fig. 17. Influence of Reynolds number on the Bejan number fields in the enclosure under study

One of the important geometric parameters that can have a significant effect on the flow irreversibility in the enclosure under study is the inclination angle of side walls $(\Phi)$. For a more detailed analysis of this issue, variations of the entropy generations number on the bottom wall of enclosure are plotted in Figure 18 at three different values of $\Phi$. A dual trend is seen from this figure for the variations of the entropy generations number in terms of the inclination angle of side walls. In fact, the effects of the inclination angle of side walls on the entropy generations number is similar to the influences of Reynolds number on it which have been explained before. However, it is clear from Figure 18 that the maximum magnitudes of entropy generation number on the bottom wall increases as the inclination angle of side wall enhances.

To further analysis the influences of inclination angle of side walls on the rates of flow irreversibility, the magnitudes of total entropy generation number in the whole computational domain of studied enclosure are presented in Figure 19. As can be seen from this figure, the values of the total entropy generation number increase with enhancement of inclination angle of side 
wall. Therefore, it can be said that the maximum values of total entropy generation number occurs in the enclosure with high values of the inclination angle of side walls.

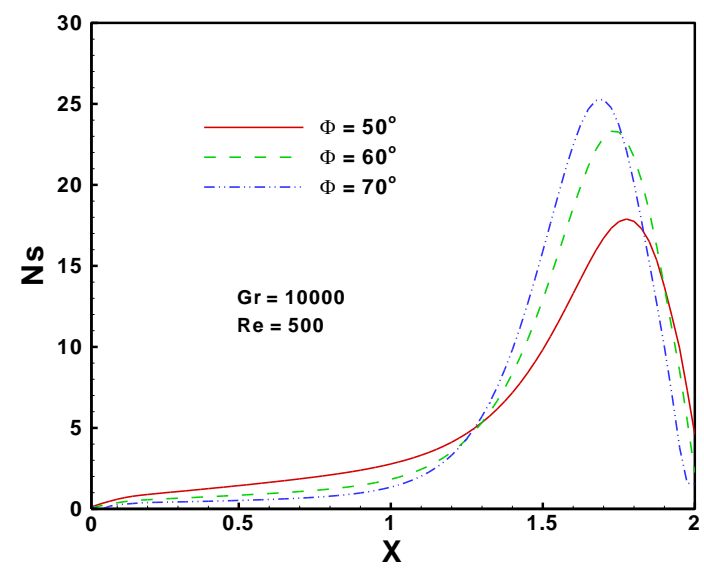

Fig. 18. Influence of the inclination angle of side walls on the distributions of entropy generation numbers along the bottom wall of enclosure under study

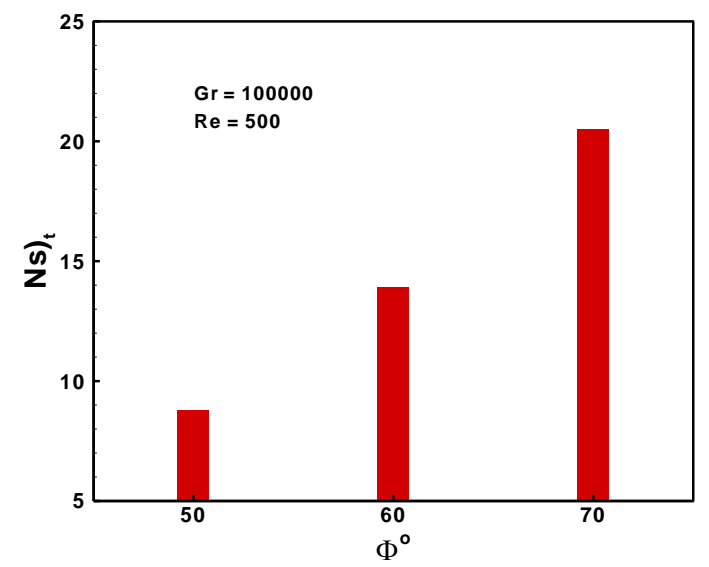

Fig. 19. Influence of the inclination angle of side walls on the values of total entropy generation numbers along the bottom wall of enclosure under study

\section{Conclusion}

In this paper, influences of Grashof number $(0 \leq G r \leq 200000)$, Reynolds number $(400 \leq \operatorname{Re} \leq 800)$ and inclination angle of side walls $\left(50^{\circ} \leq \Phi \leq 70^{\circ}\right)$ on the irreversibility rates of mixed convection fluid flow in a trapezoidal enclosure are studied with full details. This type of enclosure has many applications in the design of engineering and thermal systems. The analysis of the second law of thermodynamics is applied to calculate the entropy generation numbers. Also, the diagonal walls of the trapezoidal enclosure are accurately modeled according to the modified blocked region method. The results of this study can be summarized as follows: 
$\checkmark$ The modified blocked region method has a very high ability to simulate different surfaces in Cartesian coordinates. Such that, the calculations obtained from this method are very consistent with the results of previous studies.

$\checkmark$ The values of the entropy generation numbers on the bottom wall of the enclosure increase as the Grashof number increases.

$\checkmark$ The Reynolds number and inclination angle of side walls have a dual influence on the magnitudes of the entropy generation numbers on the bottom wall.

$\checkmark$ Any enhancement in the values of Grashof number, Reynolds number and inclination angle of side walls leads to a significant increase in the magnitudes of total entropy generation number (the flow irreversibility). Therefore, the optimal conditions for the design of thermal systems with a trapezoidal enclosure are related to the case of forced convection flow $(G r=0)$ with the lowest values of Reynolds number $(\operatorname{Re}=400)$ and the inclination angle of side walls $\left(\Phi=50^{\circ}\right)$.

$\checkmark$ The contribution of conductive heat transfer in the values of total entropy generation numbers (Bejan number) increases and decreases with increasing the Reynolds number and Grashof number, respectively.

\section{Nomenclature}

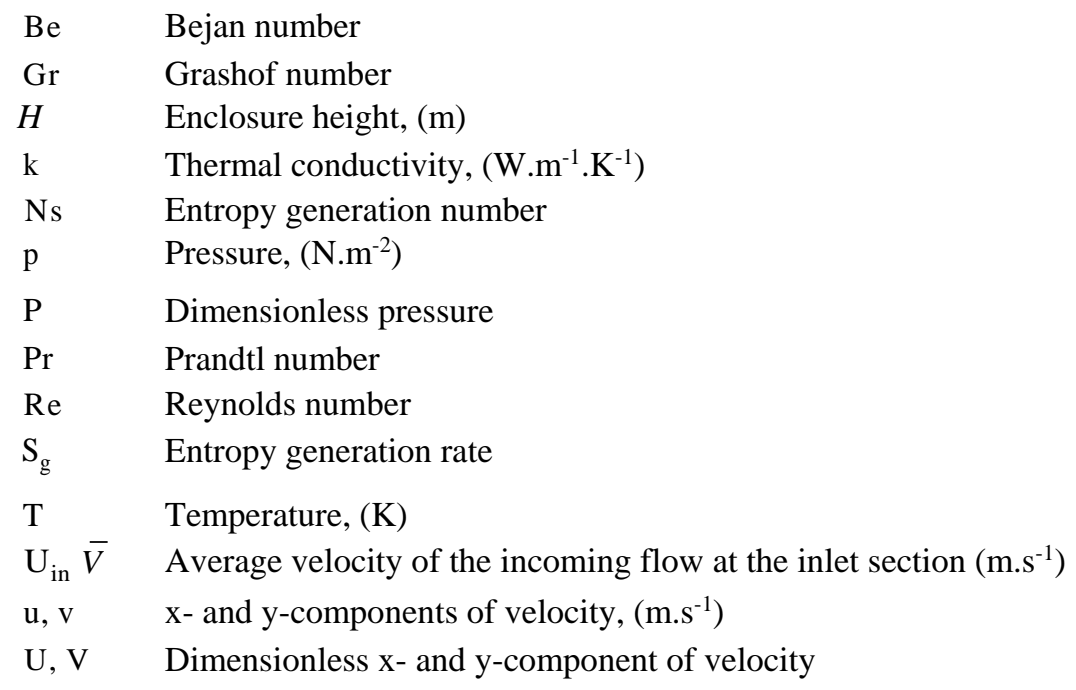

\section{Greek Symbols}

$\begin{array}{ll}\alpha & \text { Thermal diffusivity, }\left(\mathrm{m}^{2} \cdot \mathrm{s}^{-1}\right) \\ \beta & \text { Constant volumetric expansion } \\ \mu & \text { Dynamic viscosity, }\left(\mathrm{N} . \mathrm{s} \cdot \mathrm{m}^{-2}\right) \\ v & \text { Kinematic viscosity, }\left(\mathrm{m}^{2} \cdot \mathrm{s}^{-1}\right) \\ \rho & \text { Density, }\left(\mathrm{kg} \cdot \mathrm{m}^{-3}\right) \\ \Theta & \text { Dimensionless temperature }\end{array}$




\section{References}

Aghaei A, Khorasanizadeh H, Sheikhzadeh G, Abbaszadeh M (2016). Numerical study of magnetic field on mixed convection and entropy generation of nanofluid in a trapezoidal enclosure. Journal of Magnetism and Magnetic Materials. 403: 133-145.

Ali MM, Alim MA, Ahmed SS (2017). Magnetohydrodynamic mixed convection flow in a hexagonal enclosure. Procedia engineering. 194: 479-486.

Atashafrooz M, Nassab SG (2013). Simulation of laminar mixed convection recess flow combined with radiation heat transfer. Iranian Journal of Science and Technology, Transactions of Mechanical Engineering. 37(M1): 71-75.

Atashafrooz M, Gandjalikhan Nassab SA, Ansari AB (2014). Numerical investigation of entropy generation in laminar forced convection flow over inclined backward and forward facing steps in a duct under bleeding condition. Thermal Science. 18(2): 479-492.

Atashafrooz M, Asadi T (2019). The effects of buoyancy force on the irreversibility of threedimensional step flow in an inclined duct. Journal of the Serbian Society for Computational Mechanics. 13(1): 1-16.

Atashafrooz M, Sheikholeslami M, Sajjadi H, Delouei AA (2019). Interaction effects of an inclined magnetic field and nanofluid on forced convection heat transfer and flow irreversibility in a duct with an abrupt contraction. Journal of Magnetism and Magnetic Materials. 478: 216-226.

Atashafrooz M, Sajjadi H, Delouei AA (2020). Interacting influences of Lorentz force and bleeding on the hydrothermal behaviors of nanofluid flow in a trapezoidal recess with the second law of thermodynamics analysis. International Communications in Heat and Mass Transfer. 110: 104411.

Bahaidarah HMS, Sahin AZ (2013). Thermodynamic analysis of fluid flow in channels with wavy sinusoidal walls. Thermal Science. 17(3): 813-822.

Bhattacharya M, Basak T, Oztop HF, Varol Y (2013). Mixed convection and role of multiple solutions in lid-driven trapezoidal enclosures. International Journal of Heat and Mass Transfer. 63: 366-388.

Bejan A (1994). Entropy generation through heat and fluid flow. John Wiley \& Sons Inc., Canada. Bejan A (1996). Entropy generation minimization. CRC Press, Boca Raton, New York, USA.

Chamkha AJ, Rashad AM, Alsabery AI, Abdelrahman ZMA, Nabwey HA (2020). Impact of partial slip on magneto-ferrofluids mixed convection flow in enclosure. Journal of Thermal Science and Engineering Applications. 12(5): 051002.

Dagtekin I, Oztop HF, Bahloul A (2007). Entropy generation for natural convection in $\Gamma$-shaped enclosures. International Communications in Heat and Mass Transfer. 34 (4): 502-510.

Dutta S, Biswas AK, Pati S (2018). Natural convection heat transfer and entropy generation inside porous quadrantal enclosure with nonisothermal heating at the bottom wall. Numerical Heat Transfer, Part A: Applications. 73(4): 222-240.

Erbay LB, Altaç Z, Sülüş B (2004). Entropy generation in a square enclosure with partial heating from a vertical lateral wall. Heat and Mass Transfer. 40(12): 909-918.

Ismael MA, Pop I, Chamkha AJ (2014). Mixed convection in a lid-driven square cavity with partial slip. International Journal of Thermal Sciences. 82: 47-61.

Iwatsu R, Hyun JM, Kuwahara K (1993). Mixed convection in a driven cavity with a stable vertical temperature gradient. International Journal of Heat and Mass Transfer. 36(6): 16011608.

Kefayati GHR, Hosseinizadeh SF, Gorji M, Sajjadi H (2012). Lattice Boltzmann simulation of natural convection in an open enclosure subjugated to water/copper nanofluid. International Journal of Thermal Sciences. 52: 91-101. 
Kooshki MS, Gandjalikhan Nassab SA, Ansari AB (2012). Investigation of entropy generation in 3-d laminar forced convection flow over a backward facing step with bleeding. International Journal of Engineering-Transactions A: Basics. 25(4): 379-388.

Mahmoodabadi MJ, Mahmoodabadi F, Atashafrooz M (2018). Development of the meshless local Petrov-Galerkin method to analyze three-dimensional transient incompressible laminar fluid flow. Journal of the Serbian Society for Computational Mechanics. 12(2): 128-152.

Malik S, Nayak AK (2017). MHD convection and entropy generation of nanofluid in a porous enclosure with sinusoidal heating. International Journal of Heat and Mass Transfer. 111: 329-345.

Mamourian M, Shirvan KM, Ellahi R, Rahimi AB (2016). Optimization of mixed convection heat transfer with entropy generation in a wavy surface square lid-driven cavity by means of Taguchi approach. International Journal of Heat and Mass Transfer. 102: 544-554.

Mohaghegh MR, Esfahani JA (2016). Entropy generation analysis of free convection from a constant temperature vertical plate using similarity solution. Thermal Science. 20(6): 18551866.

Mohammadi M, Nassab SAG (2015). The combined heat transfer of radiation and mixed convection analysis in a lid-driven trapezoidal cavity. Journal of Theoretical and Applied Mechanics. 53(3): 643-652.

Nithyadevi N, Begum AS (2017). Effect of magnetic field on mixed convection flow in a porous enclosure using nanofluids. International Journal of Applied and Computational Mathematics. 3(4): 3433-3442.

Oztop HF, Kolsi L, Alghamdi A, Abu-Hamdeh N, Borjini MN, Aissia HB (2017). Numerical analysis of entropy generation due to natural convection in three-dimensional partially open enclosures. Journal of the Taiwan Institute of Chemical Engineers. 75: 131-140.

Patankar SV, Spalding DB (1972). A calculation procedure for heat, mass and momentum transfer in three-dimensional parabolic flows. International Journal of Heat and Mass Transfer. 15(10): 1787-1806.

Revnic C, Grosan T, Pop I, Ingham DB (2011). Magnetic field effect on the unsteady free convection flow in a square cavity filled with a porous medium with a constant heat generation. International Journal of Heat and Mass Transfer. 54(9-10): 1734-1742.

Sajjadi H, Delouei AA, Atashafrooz M, Sheikholeslami M (2018). Double MRT Lattice Boltzmann simulation of 3-D MHD natural convection in a cubic cavity with sinusoidal temperature distribution utilizing nanofluid. International Journal of Heat and Mass Transfer. 126: 489-503.

Sajjadi H, Delouei AA, Sheikholeslami M, Atashafrooz M, Succi S (2019). Simulation of three dimensional MHD natural convection using double MRT Lattice Boltzmann method. Physica A: Statistical Mechanics and its Applications. 515: 474-496.

Seyyedi SM, Dogonchi AS, Hashemi-Tilehnoee M, Waqas M, Ganji DD, (2020). Entropy generation and economic analyses in a nanofluid filled L-shaped enclosure subjected to an oriented magnetic field. Applied Thermal Engineering. 168:114789.

Sheikholeslami M, Sajjadi H, Delouei AA, Atashafrooz M, Li Z (2019). Magnetic force and radiation influences on nanofluid transportation through a permeable media considering A12O3 nanoparticles. Journal of Thermal Analysis and Calorimetry. 136(6): 2477-2485.

Stiebler M, Krafczyk M, Freudiger S, Geier M (2011). Lattice Boltzmann large eddy simulation of subcritical flows around a sphere on non-uniform grids. Computers \& Mathematics with Applications. 61(12): 3475-3484.

Wu H, Wang J, Tao Z (2011). Passive heat transfer in a turbulent channel flow simulation using large eddy simulation based on the lattice Boltzmann method framework. International journal of Heat and Fluid Flow. 32(6):1111-1119. 
Yu Q, Xu H, Liao S (2018). Analysis of mixed convection flow in an inclined lid-driven enclosure with Buongiorno's nanofluid model. International Journal of Heat and Mass Transfer. 126: 221-236.

Zabihi M, Lari K, Amiri H (2017). Comparison of the blocked-off and embedded boundary methods in radiative heat transfer problems in $2 \mathrm{D}$ complex enclosures at radiative equilibrium. Journal of Mechanical Science and Technology. 31(7): 3539-3551. 